\title{
A phylogenomic profile of globins
}

\author{
Serge N Vinogradov*1, David Hoogewijs², Xavier Bailly³, Raúl Arredondo- \\ Peter $^{4}$, Julian Gough 5 , Sylvia Dewilde ${ }^{6}$, Luc Moens ${ }^{6}$ and \\ Jacques R Vanfleteren ${ }^{2}$
}

\begin{abstract}
Address: ${ }^{1}$ Department of Biochemistry and Molecular Biology, Wayne State University School of Medicine, Detroit, MI 48201, USA, ${ }^{2}$ Department of Biology, Ghent University, B-9000 Ghent, Belgium, ${ }^{3}$ Station Biologique de Roscoff, 29680 Roscoff, France, ${ }^{4}$ Laboratorio de Biofísica y Biología Molecular, Facultad de Ciencias, Universidad Autónoma del Estado de Morelos, 62210 Cuernavaca, Morelos, México, ${ }^{5}$ RIKEN Genomic Sciences Centre, Yokohama 230-0045, Japan and ${ }^{6}$ Department of Biomedical Sciences, University of Antwerp, 2610 Antwerp, Belgium

Email: Serge N Vinogradov* - svinogra@med.wayne.edu; David Hoogewijs - david.hoogewijs@UGent.be; Xavier Bailly - bailly@sb-roscoff.fr; Raúl Arredondo-Peter - normanac@terra.com.mx; Julian Gough - gough@gsc.riken.jp; Sylvia Dewilde - sylvia.dewilde@ua.ac.be;

Luc Moens - luc.moens@ua.ac.be; Jacques R Vanfleteren - jacques.vanfleteren@UGent.be

* Corresponding author
\end{abstract}

\section{Published: 07 April 2006}

BMC Evolutionary Biology2006, 6:31 doi:10.1 |86/|47|-2|48-6-31

This article is available from: http://www.biomedcentral.com/I47I-2I48/6/3I

(c) 2006Vinogradov et al; licensee BioMed Central Ltd.

This is an Open Access article distributed under the terms of the Creative Commons Attribution License (http://creativecommons.org/licenses/by/2.0), which permits unrestricted use, distribution, and reproduction in any medium, provided the original work is properly cited.
Received: 15 December 2005

Accepted: 07 April 2006

\begin{abstract}
Background: Globins occur in all three kingdoms of life: they can be classified into single-domain globins and chimeric globins. The latter comprise the flavohemoglobins with a C-terminal FADbinding domain and the gene-regulating globin coupled sensors, with variable $\mathrm{C}$-terminal domains. The single-domain globins encompass sequences related to chimeric globins and «truncated» hemoglobins with a 2 -over-2 instead of the canonical 3-over-3 $\alpha$-helical fold.

Results: A census of globins in 26 archaeal, 245 bacterial and 49 eukaryote genomes was carried out. Only $\sim 25 \%$ of archaea have globins, including globin coupled sensors, related single domain globins and 2-over-2 globins. From one to seven globins per genome were found in $\sim 65 \%$ of the bacterial genomes: the presence and number of globins are positively correlated with genome size. Globins appear to be mostly absent in Bacteroidetes/Chlorobi, Chlamydia, Lactobacillales, Mollicutes, Rickettsiales, Pastorellales and Spirochaetes. Single domain globins occur in metazoans and flavohemoglobins are found in fungi, diplomonads and mycetozoans. Although red algae have single domain globins, including 2-over-2 globins, the green algae and ciliates have only 2-over-2 globins. Plants have symbiotic and nonsymbiotic single domain hemoglobins and 2-over-2 hemoglobins. Over $90 \%$ of eukaryotes have globins: the nematode Caenorhabditis has the most putative globins, $\sim 33$. No globins occur in the parasitic, unicellular eukaryotes such as Encephalitozoon, Entamoeba, Plasmodium and Trypanosoma.
\end{abstract}

Conclusion: Although Bacteria have all three types of globins, Archaeado not have flavohemoglobins and Eukaryotes lack globin coupled sensors. Since the hemoglobins in organisms other than animals are enzymes or sensors, it is likely that the evolution of an oxygen transport function accompanied the emergence of multicellular animals. 


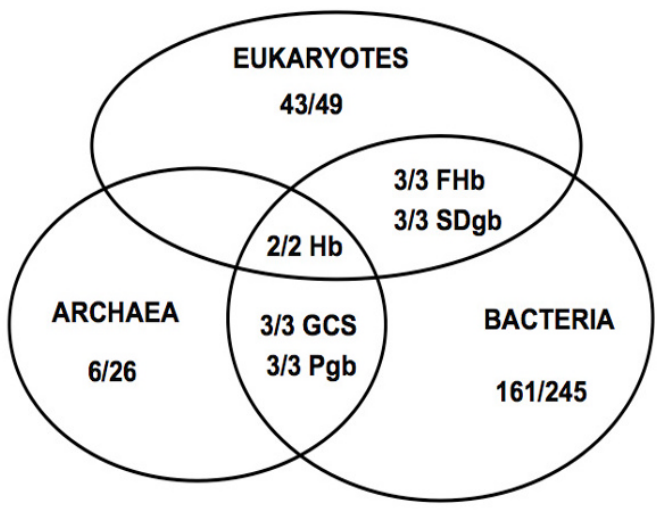

Figure I

A Venn diagram of the distribution in the three kingdoms of life, of the three globin lineages: 3/3 FHbs/SDgbs, 3/3 GCSs/ Pgbs and $2 / 2 \mathrm{Hbs}$. The number of genomes that have globins is shown as a fraction of the total number of genomes.

\section{Background}

The number of globin families has grown markedly since the 1970 's, when they were limited to the $\alpha$-and $\beta$-globins and Mbs, mostly of vertebrates, and the SHbs (legHbs) of legume plants [1-3]. The ensuing years brought to light several new globins: SHbs in plants other than legumes, NsHbs in a wide variety of plants [4-6], and FHbs, chimeric proteins ( 400aa) comprising an N-terminal globin domain and a C-terminal FAD- and NAD-binding domain, related to the ferredoxin-NADP+ reductases, found in E. coli [7] and in yeasts [8,9]. Concurrently, "truncated" globins, sequences shorter than normal (<130aa), were discovered in protozoa [10], cyanobacteria [11-13], a nemertean [14], and bacteria [15,16]. Globins longer than normal (>160aa), similar to the "truncated" Hbs, were observed in a green alga $[17,18]$ and in plants [19]. The crystal structures of several "truncated" Hbs showed them to have a novel 2-over-2 $\alpha$-helical fold instead of the canonical 3-over-3 $\alpha$-helical fold, with an abbreviated A helix, a decreased CE interhelical region and most of the F helix occurring as a loop [20-22]. Consequently, we advocate using $2 / 2 \mathrm{Hb}$ instead of "truncated", to indicate the distinctive secondary structure of this group of globins and to bring order to the chaotic terminology in the existing databases, where "truncated", "cyanobacterial", "protozoan" and "2-over-2" are all in current use.

The utilization of molecular biological techniques allowed the detection of globins in organisms where their presence was unsuspected, such as the nematode Caenorhabditis elegans and in other nematodes [23-30], the dipteran Drosophila melanogaster [31] and the urochordate Ciona intestinalis [32]. The recent, rapid accumulation of genomic information has resulted in a substantial increase in newly recognized globins. This list includes the Ngbs [33,34] and Cygbs [35-37], which are believed to occur in all vertebrates from humans to birds and fish [38], GbE, the eye-specific globin in the domestic chicken Gallus gallus, related to Cygb [39], and GbX, a new and fifth type of globin gene in fish and amphibians, thought to have been lost in the higher vertebrates [40]. FHbs were found in a variety of bacterial groups [16,41-43] together with SDgbs, which align with the FHb globin domains $[42,43]$. Furthermore, globin coupled sensor proteins, chimeric two-domain gene regulators ( 300 to $>700 \mathrm{aa})$ comprising an N-terminal globin domain, were discovered in an archaean and several bacterial groups [44-47]. Lastly, "protoglobins" ( 195aa) related to the former, were found in archaea and in several bacteria [48] and proposed to represent the "ancestral" globin.

\section{Results \\ Overview}

The 245 bacterial, 26 archaeal and 49 eukaryote genomes, and the identified known and putative globins, are listed in Supplemental Data Tables 1-6 [see Additional File 1]. An alignment of the sequences is provided in Supplemental Data Fig. 1 [see Additional File 2]. All the globins identified in our survey can be assigned to two general classes: single chain globins and globin domains within chimeric proteins. The former group comprises the vertebrate $\alpha$ and $\beta$-globins, Mbs, Ngbs and Cygbs, the metazoan intraand extracellular Hbs (including multi-domain and/or multisubunit Hbs), the plant SHbs and NsHbs, the 195aa Pgbs and the 2/2 Hbs. The two groups of chimeric proteins, which generally have an N-terminal globin domain, are the 400 aa FHbs with an NAD and FADbinding C-terminal domain, and the GCSs with highly variable ( $\sim 50$ to $>700 \mathrm{a}$ ) C-terminal domains. Thus, all globins belong to one of three globin lineages: the $3 / 3$ FHbs and SDgbs (eukaryote and bacterial), the 3/3 GCSs and Pgbs and the 2/2 SDgbs [49]. Fig. 1 provides the number of genomes that have globins and illustrates a key result: only one of the three globin lineages, the 2/2 Hbs, are represented in all three kingdoms of life. Fig. 2 shows the approximate phylogenetic relationships between the main groups of the three kingdoms of life based on Baldauf et al. [50] and depicts the phylogenomic profile of globins.

It should be emphasized, that the presence of putative globins inferred using SUPERFAMILY and blastp and psiblast searches of the GenBank database, does not require having a completed genome. On the other hand, the absence of a globin is certain only when a complete genome is searched and no sequence is found. 


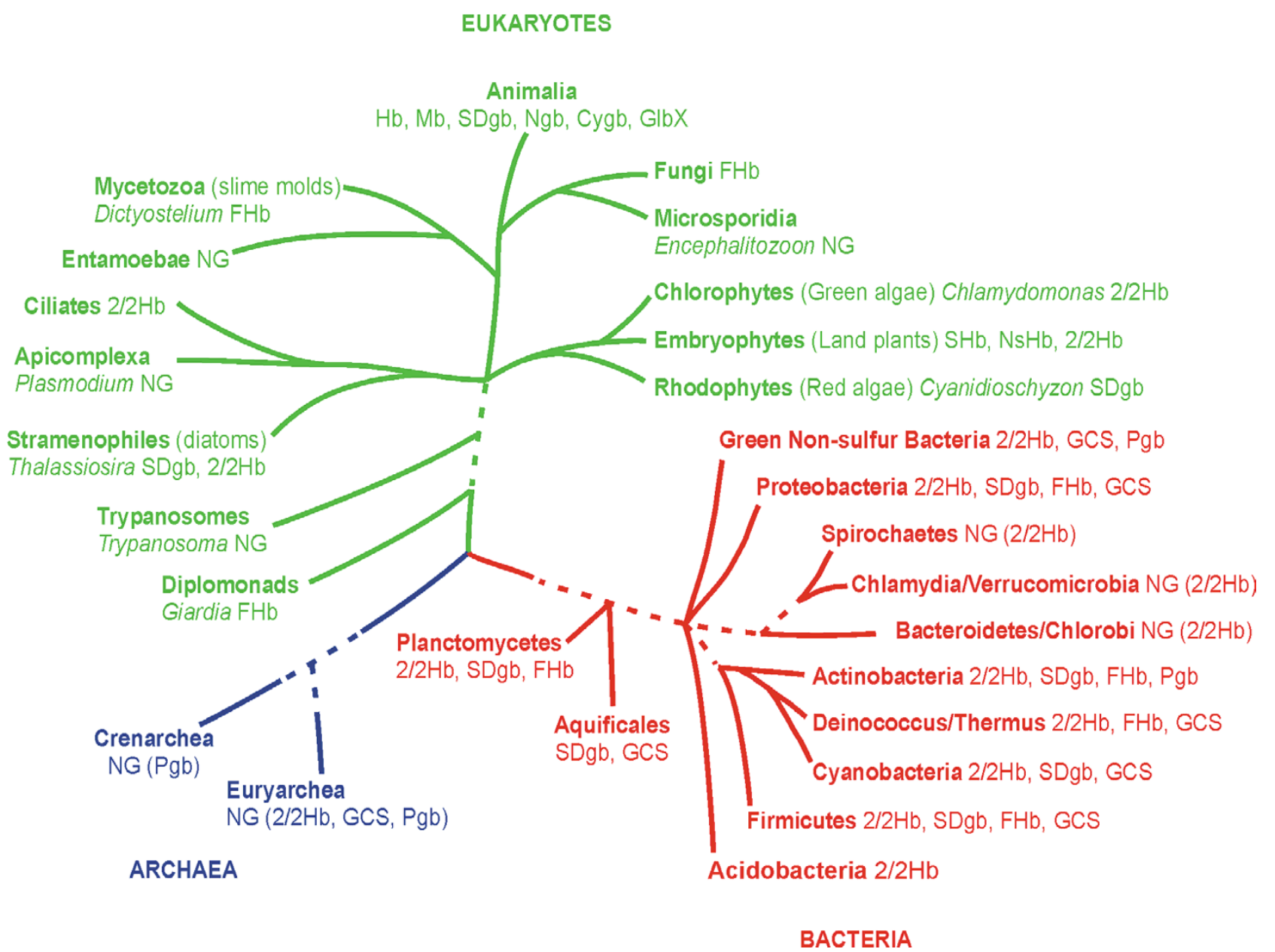

Figure 2

A diagrammatic representation of the three kingdoms of life and the phylogenetic relationships of their major groups based on Baldauf et al. [50], and depicting the distribution of globins.

\section{Archaea}

Table 2 in the Supporting Data [see Additional File 1] lists the archaeal genomes, their sizes and the presence of globins. SUPERFAMILY identified putative globins in four Archaea: Halobacterium, Methanobacterium, Methanosarcina and Sulfolobus. In addition, another globin was identified in the SWISSPROT/TrEMBL database (tr|Q96ZL6). Examination of these sequences showed that they are not likely to be globins due to lack of size (<100aa) and/or the absence of a suitable F8His. However, Hou et al.
$[44.45,48]$ have recently discovered GCSs and Pgbs in a couple of archaea, and we found a 2/2 Hb1 in Haloarcula marismortui [49]. This survey has uncovered a 2/2 Hb1 in still another euryarcheote halophile Haloferax volcanii. Thus, only five of the 20 Euryarcheote genomes have globins: Haloarcula marismortui (2/2 Hb1, GCS), Halobacterium salinarum (GCS), Haloferax volcanii (2/2 Hb1, GCS), Methanosarcina acetivorans and M. barkeri (Pgbs). Of the 5 Crenarcheote genomes, only Aeropyrum pernix, has a globin (Pgb) and the only Nanoarcheote genome has no globins. 
Table I: Number of bacterial genomes with one or more classes of. 2-over-2 Hbs

\begin{tabular}{cccccc}
\hline Class I & Class 2 & Class 3 & Class I+2 & Class I+3 & Class 2+3 \\
\hline 17 & 47 & 18 & 14 & 1 & 18 \\
\hline
\end{tabular}

The paucity of globins in Archaea is one of the surprising results of our survey. Except for Aeropyrum pernix, the archaeal genomes comprising globins are, coincidentally, among the largest known archaeal genomes. It is interesting to note that none of the GCSs or Pgbs have been identified by the hidden Markov chain model used by SUPERFAM, although they align readily with the globin fold, based on the recent crystal structure of Bacillus subtilis GCS [51]. Most of the archaeal genomes sequenced to date have been those of extremophilic organisms with small genomes. It is now known that there are many more non-thermophilic terrestrial and marine archaea than hitherto suspected [52]. It remains to be seen whether additional archaeal genomes will reverse the situation.

\section{Bacteria}

Table 3 in Supporting Data [see Additional File 1] lists the completed and unfinished bacterial genomes used in this study, their sizes, the type and number of globins present, 2/2 Hbs (classes 1, 2 and 3), FHbs (SDgbs) and GCSs (Pgbs), and the oxygen requirement and habitat of the organism. A diagrammatic representation of the phylogenetic relationships between the main bacterial groups based on Baldauf et al. [50], shown in Fig. 3, summarizes the globin distribution among the bacteria. The one representative of the Acidobacteria has globins, and only 4 of the 26 genomes representing the Actinomycetes have none: Bifidobacterium, Propionibacterium, Symbiobacterium and Trophyrema. The 3 Aquificales/Thermotogales have globins except Thermotoga, and the 5 Bacteroidetes/Chlorobi (except Cytophaga) lack globins, as well as the 6 Chlamydiae/Verrumicrobium genomes, except Parachlamydia and Verrumicrobium. Of the 3 Chloroflexi genomes, Dehalococcoides, has no globins. The Cyanobacteria are represented by 12 genomes, of which 5 lack globins: Anabaena, Crocosphaera, Prochlorococcus, Synechocccus elongatus and Trichodesmium. Both Deinococcus and Thermus have globins. Among the 49 Firmicutes, apart from the Lactobacillales and the Mollicutes, the 17 Bacilli have globins (except Listeria), as well as 4 of the 7 Clostridia. Although Fusobacterium lacks globins, the lone Nitrospirae and the two Planctomycetes have globins. The majority of the 35 genomes of Alphaproteobacteria have globins: all the Caulobacterales, Rhizobiales (except Bartonella), Rhodobacterales, Rhodospirilalles and Sphingomonadales, but only one of the 10 Rickettsiales (Pelagibacter ubique). All 24 genomes representing the Betaproteobacteria have globins, except 2 of the 4 Neisseriaceae. The 50 Gammaproteobacteria genomes represent 10 groups, of which only 3 of the 10 Enterobacteriales (Buchnera, Blochmannia and Wigglesworthia), one of two Legionellales, the 5 Pasteurellales, the two Psychrobacter of the 10 Pseudomonadales, and the one Thiotrichales (Francisella) are devoid of globins. The 10 genomes of Deltaproteobacteria have globins, except for Desulfovibrio. Two of the 8 genomes representing the Epsilonproteobacteria have no globins: Helicobacter pylorii and Wolinella; however, Helicobacter hepaticus has a globin. The lone unassigned proteobacterium Magnetococcus has a GCS. Of the 128 genomes representing the Proteobacteria, 99 have globins $(\sim 75 \%)$.

Alignment of bacterial $2 / 2 \mathrm{Hb}$ sequences indicates that they can be divided into three separate classes $[16,53]$. The length of the $2 / 2$ Hbs varies from 118 aa for the cyanobacterium Nostoc (ZP_00112318) to 260aa in Streptomyces avermitilis (NP_824492), with the majority $(>60)$ being $<140$ aa. Examination of coexistence of the three classes of $2 / 2$ Hbs (Table 1) shows an interesting trend: although only the Alphaproteobacterium Hyphomonas neptunium has both 1 and 3 and two have all three classes, 14 genomes have classes 1 and 2 and 18 have classes 2 and 3 . These results suggest that the class 1 and $32 / 2 \mathrm{Hbs}$ are derived from the class $22 / 2 \mathrm{Hbs}$, as pointed out very recently by Vuletich and Lecomte [53].

The finding of an FHb in E. coli [7] led to the discovery of some 30 bacterial FHbs $[16,42,43,54]$; currently, the number is over 70 (Supplementary Data Table 3). R. Poole and his group [43] and Frey and Kallio [42] were the first to point out the similarity between the FHb globin domains, the first bacterial $\mathrm{Hb}$ to be sequenced, that of Vitreoscilla stercoraria [55], and several other SD bacterial globins. We now have a total of 25 SDgbs in 22 genomes. The crystal structures of the P. aeruginosa (PDB: 1tu9) [56] and Vitreoscilla stercoraria (PDB: 2vhb) [57],

Table 2: Coexistence of FHbs with SDgbs in bacterial genomes.

\begin{tabular}{ccc}
\hline FHb only & SDgb only & FHb+SDgb \\
\hline 65 & 18 & 6 \\
\hline
\end{tabular}


Table 3: Coexistence of FHbs/SDgbs with 2-over-2 Hbs in bacterial genomes.

\begin{tabular}{ccccccc}
\hline FHb or SDgb only & With class I & With class 2 & With class 3 & With class I+2 & With class I+3 & With class 2+3 \\
\hline 26 & 4 & 29 & 7 & 2 & 0 & 13 \\
\hline
\end{tabular}

show them to be very similar to the globin domains of the FHbs from E. coli (PDB: 1gvh) [58] and Ralstonia (Alcaligenes) eutropha (PDB: 1cqX) (59]. It is appropriate to note here that Ralstonia has undergone two name alterations recently, to Wautersia eutropha and now to Cupriavidus necator [60]. Although 22 genomes have SDgbs, three of them have two different globins: Bradyrhizobium, Rhodopseudomonas and Novosphingobium. Table 2 shows that FHbs and SDgbs coexist in only 6 genomes: Chromobacte- rium, Photobacterium, Pseudomonas aeruginosa, Rhodopirellula, Thermobifida and Vibrio parahaemolyticus. Table 3 shows the statistics of occurrence of $2 / 2$ Hbs with the FHbs/SDgbs; the latter tend to occur with class 2 and with both class 2 and $32 / 2$ Hbs.

M. Alam and his group have identified 27 GCSs [46,47] and 3 Pgbs from bacteria - Chloroflexus aurantiacus ZP_00359040 (227aa), Thermobifida fusca ZP_00293478

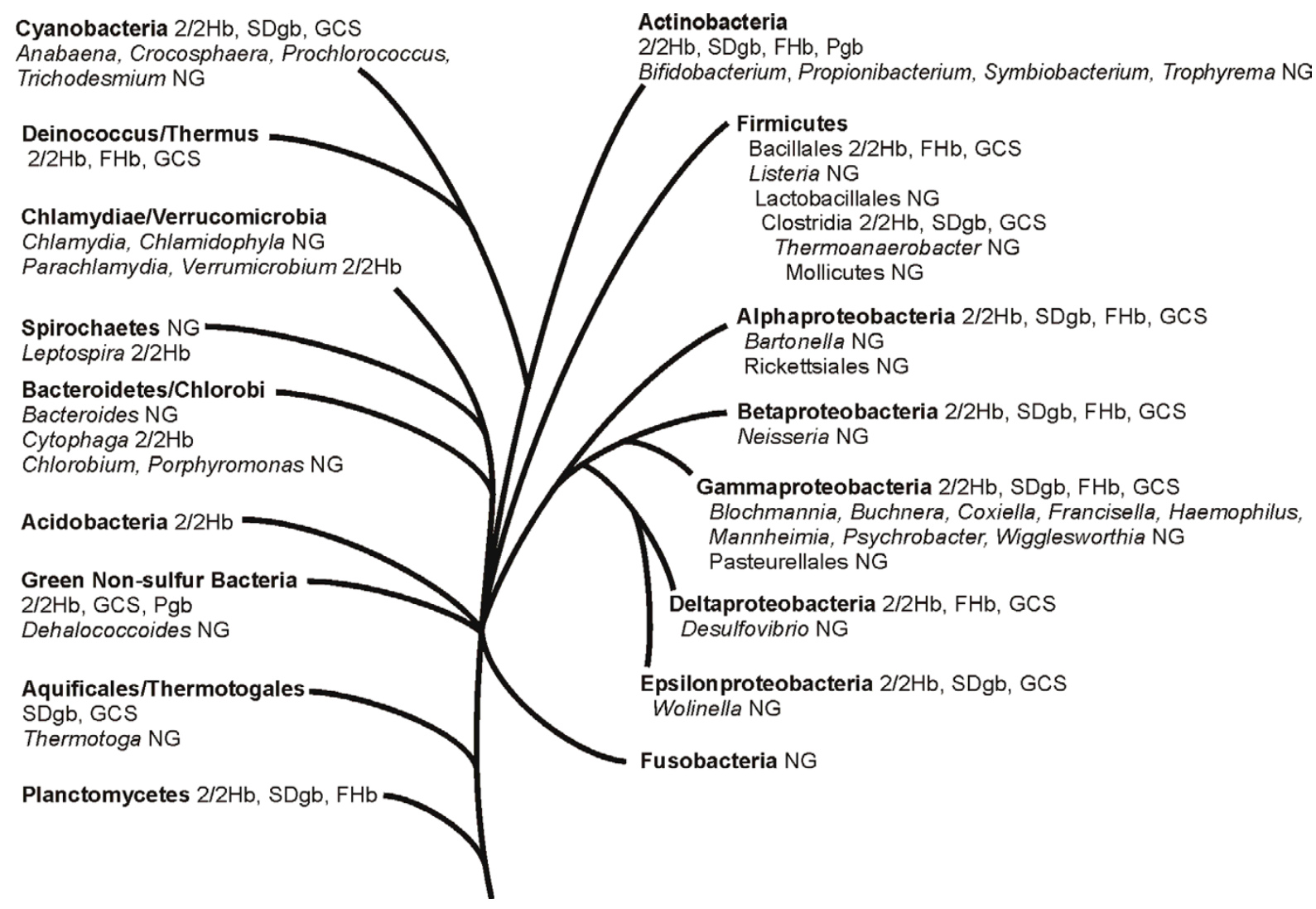

Figure 3

A diagrammatic representation of the phylogenetic relationships between the major bacterial groups based on Baldauf et al.[50], and showing the distribution of globins. 

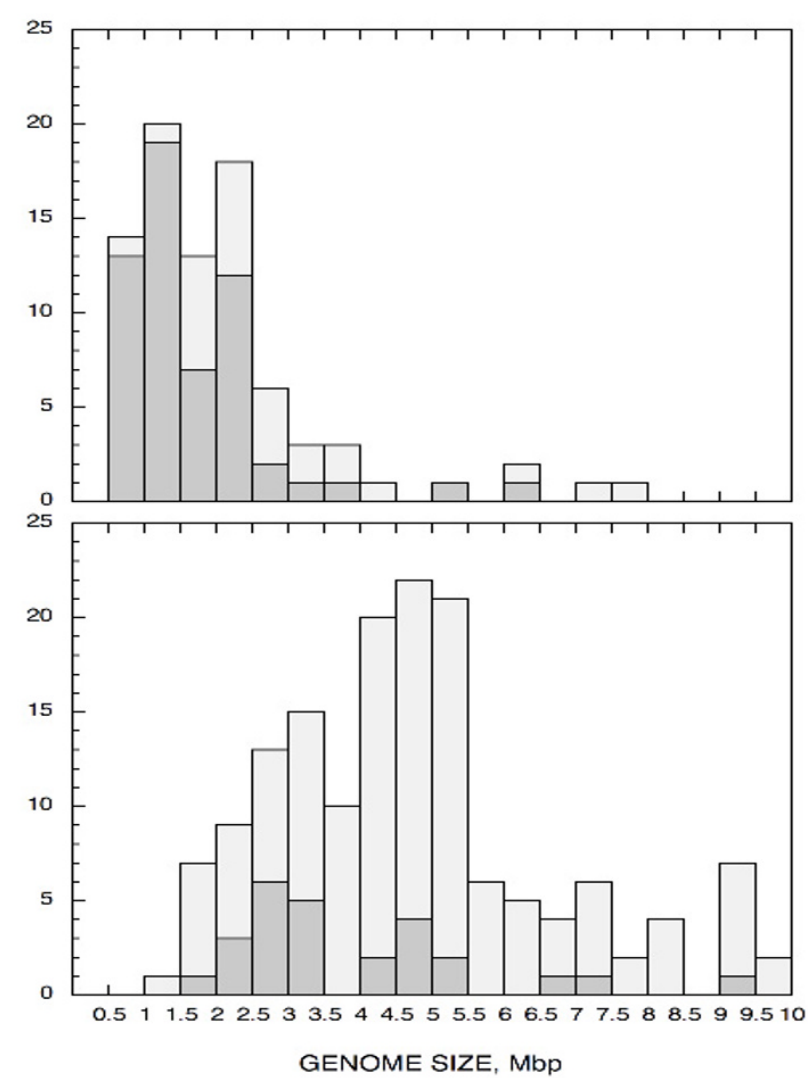

\section{Figure 4}

The statistics of bacterial genome size distribution: lacking globins (upper panel) and containing globins (lower panel). The genomes that are host-associated (Table 3 in Supplementary Material) are represented by stippled bars.

(197aa) and Thermosynechococcus elongatus NP_682779 (194aa) [48]. Blastp searches found an additional two dozen GCSs, and Pgbs in Thermus thermophilus YP_005074 (203aa) and the actinobacterium Rubrobacter xylanophilus ZP_00200180 (196aa) [49,61]. The recent crystal structure of $B$. subtilis GCS shows it to have a $3 / 3$ fold

The genomes with the largest number of globins, 5 to 7 , are all from the Alpha- and Betaproteobacteria; they do include however, redundant sequences. The following have all three lineages of globins:Burkholderia fungorum (9.67 Mbp), Chromobacterium violaceum (4.75 Mbp), Novosphingobium aromaticivorans (4.21 Mbp) and Silicibacter sp.TM1040 (4.14 Mbp), each with 5 globins, the three Bordetella species (4.09-5.34 Mbp), Exiguobacterum sp.255-15 (2.89 Mbp), Shewanella baltica (5.01 Mbp), Sinorhizobium meliloti and Thermobifida fusca (3.64 Mbp), each with 4 globins, and Azotobacter vinelandii (5.42 Mbp), all the Bacillus species (except B. licheniformis and $B$. stearothermophilus) (4.20-5.50 Mbp) and Geobacillus kaus- tophilus (3.59 Mbp), each with 3 globins. At the other end of the scale, the smallest genome (1.31 Mbp) to have a globin, a 2/2 Hb1, is that of the marine Alphaproteobacterium Pelagibacter ubiques (Rickettsiales), followed by Aquifex aeolicus (1.59 Mbp), and the Epsilonbacterium Campylobacter jejuni (1.64 Mbp), with one (SDgb) and two $(2 / 2 \mathrm{Hb}$ and $\mathrm{SDgb})$ globins, respectively.

The bacterial divisions represented by 10 or more genomes, rank in the following order of having globins: Betaproteobacteria - 92\% (22/24) > Actinobacteria $85 \%(22 / 26)>$ Gammaproteobacteria - 76\% (38/50) > Alphaproteobacteria - 69\% (24/35) > Cyanobacteria $58 \%(7 / 12)>$ Firmicutes - 49\% (19/39). Overall, 161 of the $245(\sim 65 \%)$ bacterial genomes have globins and the number of globins varies from 1 to 7 .

Fig. 4 depicts the size distribution of bacterial genomes lacking globins (upper panel) and comprising globins (lower panel); the stippled columns represent the genomes associated with a host (given in Supplemental Data Table 3 [see Additional File 1]). Although the two distributions overlap, it is evident that presence of globins is correlated with genome size and that the majority of genomes lacking globins are host associated. Table 4 shows the mean genome size for completed genomes lacking globin and with one or more globins. The mean size of the genomes shows a positive correlation with the number of globins present. About 80\% (65/82) of genomes <2.5 Mbp lack globins (mean $2.1 \mathrm{Mbp}$ ). Very small genomes are characteristic of bacteria with lifestyles characterized by continuous association with a host [63]. The majority of the bacteria whose genomes have been sequenced, are human, animal and plant infectious agents. Thus, it is likely that the estimate of approximately two thirds of all bacteria having globins obtained in the present study, is on the low side.

\section{Eukaryotes}

The globins identified in eukaryote genomes are listed in Supplemental Data Tables 4-6 [see Additional File 1]. The globins listed for the vertebrate genomes, Danio (Brachydanio) rerio, Fugu (Takifugu) rubripes, Gallus gallus, Homo sapiens, Mus musculus, Rattus norvegicus and Xenopus tropicalis, include the familiar $\alpha$ - and $\beta$-globins and $M b$, as well as the recently discovered Ngbs [33,34] and Cygbs [3537]. A recent addition to human $\alpha$-globins is $\mu$-globin (gi|51510893|NP_001003938, 141aa) which appears to be very similar to the avian $\alpha$-D globin [64]. In addition, an eye-specific globin, GbE, was found in Gallus gallus [39] and a new globin, GbX, was discovered in the fish, bird and amphibian genomes [40]. Curiously, no Mb-like sequence was found in either Xenopus tropicalis or X. laevis. The zebrafish Danio rerio has 6 embryonic globins [65], three $\alpha$ and three $\beta$ - only 5 are listed in the GenBank. The 
Table 4: Number of globins found in bacterial genomes and the corresponding mean genome sizes.

\begin{tabular}{ccc}
\hline No. of globins & No of completed genomes & Mean genome size, Mbp \\
\hline 0 & 75 & $1.9 \pm 1.1$ \\
1 & 40 & $3.9 \pm 1.5$ \\
3 & 19 & $4.2 \pm 1.2$ \\
4 & 22 & $4.7 \pm 1.2$ \\
\hline
\end{tabular}

pufferfish Fugu rubripes, appears to have four $\alpha$-globin chains [66]; only three of them are listed in the GenBank.

The four globins found in the genome of the urochordate Ciona intestinalis (sea squirt), have been identified earlier [32]. This important finding corrects the erroneous claim of total absence of globins in the report of the genome [67].

At least one putative globin (gi|72169631|XP_795670, $175 \mathrm{aa})$ was found in the recently completed genome assembly of the echinoderm Strongylocentrotus purpuratus (sea urchin). Used as query in blastp searches it hits the GlbXs and Cygbs of fish, and other vertebrate Cygbs, before recognizing the coelomic globin (gi|729576;P80018) of a fellow echinoderm, the holothurian Caudina arenicola.

There appear to be 4 putative globins in Anopheles gambiae: gi|55246163| EAA03862.3 (150aa), gi|31201271|XP_309583 (192aa), gi|31198253|XP_308074 (215aa) and gi|57914327|XP_555006 (182aa). Their alignment shows that the first three are closely related, sharing essentially identical globin domains: gi|55246163 has an 18aa deletion in the $\mathrm{BC}$ helix and the $\mathrm{CD}$ corner, while gi|31198253 lacks part of the $\mathrm{G}$ and all of the $\mathrm{H}$ helices. Thus, it is likely that gi|31201271 and gi|57914327 are the only stable globins. The C-terminal 115 aa globin domain of gi|31198253 is reminiscent of the Mb gene sequence from the antarctic icefish Champsocephalus esox (gi|24266940|AAN52371, 103aa) that does not appear to be expressed [68]. It remains to be determined whether the N-terminal domain of gi|31198253 stabilizes it enough to be expressed.

At least 33 putative globins and globin domains were identified in Caenorhabditis elegans, together with their orthologs in C. briggsae [30]: they are listed in Supplemental Data Table 5 [see Additional File 1]; their alignment is provided in Supplemental Data Fig. 2 [see Additional File 2]. Several C. elegans/C. briggsae orthologs have unusually long interhelical inserts between the $\mathrm{G}$ and $\mathrm{H}$ helices: 40aa in CE01012/CBP03870) (216aa), 21 aa in CE01528 (CBP00622) (266aa), 22aa in CE34964/CBP23619 (196aa) and 21aa in CE34658/CBP07299 (230aa). Although three pairs, CE17437/CBP02580, CE04582/ CBP03989 and CE35828/CBP14482, have N-terminal globin domains, several have C-terminal domains: CE03523/СBP15914, CE04843/СBP01576, CE05316/ СВP02907, CE12774/СBP21478), СЕ36044/СВP02078), CE29586/CBP02293， CE30683/CBP02390 and CE31132/CBP15597. The N-terminal portion of the latter is identified as a $\mathrm{G}$ protein-coupled receptor-like domain with 7 putative transmembrane helices (identified using TMHMM Server V.2.0). The nonglobin domains in the remaining proteins could not be identified via blastp searches.

Although globin genes were thought to be absent in the genome of Drosophila melanogaster [69], the presence of at least one (CG9734) has been demonstrated unequivocally by Burmester and Hankeln $[31,70]$. There appear to be two more putative globins, CG15180 (209aa) and CG14675 (195aa); both provide acceptable alignments. Three putative globins are also found in D. pseudoobscura, EAL28410 (152aa), EAL28093 (641aa, 40-150) and EAL 28094 (130aa) [71], and appear to be orthologs of D. melanogaster CG9734, CG15180 and CG14675, respectively. Although the D. pseudoobscura EAL28093 and EAL28094 are scored by FUGUE as certainly globins $(Z \sim 10)$, the former lacks an appropriate F8 His residue and the latter appears to be missing the A helix. Psiblast searches show that the ortholog pairs CG15180/EAL28093 and CG14675/EAL28094) recognize each other but not the CG9734/EAL28410 pair, and also recognize the Anopheles globins (ENSANG19788, 22287 and 26474), together with distant recognition of echinoderm globins and vertebrate $\beta$-globins. The CG9734/EAL28410 pair hits the other known insect globins (Gasterophilus, Chironomus species, Kiefferulus, Tokunagayusurika), the vertebrate Cygbs and the arthropod multidomain Hbs.

Three of the four Arabidopsis thaliana sequences, GLBs 1-3 have been identified earlier [19,72]: GLB1 and GLB2 are NsHbs and GLB3 is a $2 / 2 \mathrm{Hb}$. A 693aa protein 
(gi|7486404|T04457) was found to have an N-terminal 2/2Hb domain, with the first 138 aa (up to position H13), identical to GLB3. Although the 500aa C-terminal portion does not correspond to any known protein domain(s), a blastp search using it as query found an identical sequence in the $\mathrm{N}$-terminal portion of the 2154aa protein TEBICHI (gi|62241195|BAD93700). Both proteins share the same region on Arabidopsis chromosome 4 and TEBICHI has a helicase domain at 490$890 \mathrm{aa}$ and a polymerase domain at 1700-2150aa; furthermore, this N-terminal portion is missing in animal homologues of TEB protein, MUS308/POLQ (Dr. Soichi Inagaki, personal communication).

The genome of Oryza sativa contains the four NsHbs identified by Arredondo-Peter et al. [73,74], a 172aa 2/2Hb (gi|50725383|BAD32857) and a 145aa globin (gi|50932383|XP_475719). A blastp search identified the latter as another NsHbs.

Several putative globins occur in the genome of the green alga Chlamydomonas reinhardtii: 160981 (C_240146) (136aa), 160982 (C_240147) (147aa), 157690 (C_1780015) (231aa), and two larger sequences, 168934 (C_60169) (476aa) with one N-terminal globin-like domain, and 153190 (C_100138) (837aa) with two consecutive N-terminal globin domains. Two globins were found in the genome of the diatom Phaeodactylum tricornutum: PTMM3909 and 05212. Two globins occur in the genome of another diatom Thalassiosira pseudonana, Scaffold_137 (158aa) and Scaffold_18 (160aa), and a single 185aa globin, CMR319C, in the genome of the red alga Cyanidioschyzon merolae. Blastp searches identified all the C. reinhardtii globins, the Phaeodactylum PTMM 05212 and the Thalassiosira Scaffold_18 as 2/2 Hbs, and the Cyanidioschyzon CMR319C,Phaeodactylum PTMM 3909 and Thalassiosira Scaffold_137 as SDgbs, closely related to the bacterial and fungal FHbs and the bacterial SDgbs.

The globins present in the fungi are listed in Supplemental Data Table 6 [see Additional File 1]. All the recently completed fungal genomes, which belong overwhelmingly to the Ascomycota (17 of 19), have FHbs; 14 have two to four FHbs, probably due to genome duplication [75]. In addition to Saccharomyces cerevisiae NP_014165 (426aa, 154-302) which was known to have a central globin domain [76], we found an additional 12 FHbs to have globin domains within the central portion of their sequences. All belong to the Saccharomycotina: Candida albicans EAK92722 (563aa, 298-463), Candida glabrata XP_448033 (432aa, 124-267), Eremothecium (Ashbya) gossypii NP_982746 (436aa, 184-339), Kluyveromyces lactis XP_453939 (430aa, 181-323), Kluyveromyces waltii Kwal_22190 (421aa, 171-314) Kwal_4395 (460aa, 202352) and Kwal_24852 (543, 173-315), Saccharomyces bayanus ORFP:20532(424aa, 171-303), Saccharomyces mikatae ORFP:18051 (410aa, 135-290), Saccharomyces paradoxus ORFP:18484 (426aa, 155-306) and Yarrowia lipolytica XP_502881 (463aa, 186-325) and XP_499869 (471aa, 194-333). Although the globin domains align well with the other FHbs, the $\mathrm{N}$ - and C-terminal portions do not recognize the C-terminal moieties of the other fungal and bacterial FHbs or any other known protein, as found earlier for the S. cerevisiae FHb [76]. Surprisingly, the percent identities between the CDFHbs and the fungal and bacterial FHb globin domains is about $40 \%$ and $30 \%$, respectively.

Among the lower eukaryotes, the diplomonad Giardia lamblia has one FHb [77] and the mycetozoan Dictyostelium discoideum has two [78]. The Giardia sequence has a 21aa insert between helices $\mathrm{E}$ and $\mathrm{F}$.

No globin genes appear to exist in the genomes of the Apicomplexans Entamoeba histolytica and Plasmodium falciparum, as well as the Microsporidian Encephalitozoon cuniculi and the Euglenazoan Trypanosoma brucei. Although a Plasmodium bergei globin-like protein of $228 \mathrm{aa}$ (Q86QI8) is listed in the GenBank, it is probably an artefact, since when used as a query in blastp searches, it hits only vertebrate $\beta$ - and $\alpha$-globins.

Compared to Archaea and Bacteria, the fraction of eukaryote genomes with globins is much higher, over $90 \%$. Although all vertebrates have $\mathrm{Hb}$ and $\mathrm{Mb}$ and probably $\mathrm{Ngb}$ and Cygb as well [38], the Antarctic icefish belonging to the family Channichthyidae do not express $\mathrm{Hb}$ [79]. Furthermore, at least 6 of the 16 icefish species also do not express $\mathrm{Mb}$ [80]. The lack of $\mathrm{Hb}$ is due apparently to deletion of the $\beta$-globin gene [81], which occurred during the last 10 to $16 \mathrm{Myr}$, the approximate date of divergence of the Notothenioid lineage including the Channichthyidae [82]. In contrst, the lack of $\mathrm{Mb}$ appears to be due to errors in $\mathrm{Mb}$ gene transcription [68]. It is not known whether the icefish have Ngbs and/or Cygbs. In the remaining two chordate phyla, the urochordate Ciona has 4 globins (see above), which when used as queries in psiblast searches, recognize the vertebrate globins and the eukaryote and bacterial FHbs and SDgbs. The report of a Hb in the notochord of the cephalochordate amphioxus (Branchiostoma californiense) [83], suggests that globins are present in all chordates. Among the remaining deuterostome phyla, intracellular Hbs have been reported in two of the 5 classes of echinoderms $[84,85]$, and we find a putative globin in the recent assembly of the genome from the sea urchin Strongylocentrotus purpuratus, which belongs to another class. No globins have been reported so far in hemichordates. 
Among the remaining metazoans, direct visual observation of Hbs is highly episodic among the metazoans, and varies from total absence of $\mathrm{Hb}$ in porifera and cnidaria, to frequent presence in some nematode and platyhelminth groups [3]. In the largest metazoan group, the insects, of which about 900,000 species have been described, and which outnumber the combined total of all other animal species, with estimates ranging from $2 \times$ $10^{6}$ to $100 \times 10^{6}[86]$, globins are so far known to be present only in Dipterans, such as Gasterophilus, Drosophila and Chironomus. It is evident that much work needs to be done before we have any clear idea of globin distribution in metazoans other than deuterostomes.

Among the lower eukaryotes, our census suggests that globins could be ubiquitous in fungi (FHbs), mycetozoa (FHbs), diplomonads (FHbs), ciliates (2/2 Hbs), stramenopiles (SDgb, 2/2Hb), rhodophytes (SDgb), chlorophytes $(2 / 2 \mathrm{Hb})$ and plants (SHbs, NsHbs, 2/2 Hbs). In contrast, the genomes of pathogenic microsporidians, entamoebae, apicomplexans anad trypanosomes are devoid of globins. In view of a very large potential diversity of small, bacterial-sized eukaryotes revealed by recent, culture-independent surveys $[87,88]$, much remains to be done.

Since our census indicates that GCSs do not occur in eukaryotes, it is necessary to consider the heme-regulated eukaryotic initiation factor $2 \alpha$ kinase ( 630aa), which was found recently to have two heme-binding domains, of which the N-terminal domain was considered to be globin-like $[89,90]$ Although it was demonstrated that His78 and His 123 were the two residues involved in heme binding [91], we find that the N-terminal 138aa of the rabbit protein (gi|462439|P33279|E2AK1 RABIT) is not recognized as a globin in CD or FUGUE searches. A blastp search of the GenBank database found at least 6 mammalian counterparts; clearly, a structure is required to determine whether these sequences are globins.

\section{Molecular evolution}

The broad distribution of the three lineages of globins, the $3 / 3 \mathrm{FHbs} / \mathrm{SDgbs}$, the $3 / 3 \mathrm{GCS} / \mathrm{Pgbs}$ and the $2 / 2 \mathrm{Hbs}$, is illustrated in the Bayesian phylogenetic tree shown in Fig. 5 , based on a global manual alignment of 175 sequences representing all the major groups of globins (Supplemental Data Fig. 3, [see Additional File 2]). The 2/2 Hbs and the GCSs/Pgbs cluster separately (upper left hand side), with the three classes of $2 / 2$ Hbs clearly delineated. Within the $2 / 2 \mathrm{Hb}$ clusters, the archaeal (Haloarcula), ciliate (Paramecium) and chlorophyte (Chlamydomonas) globins occur with the class 1 and the diatom (Thalassiosira) and plant (Oryza, Arabidopsis) Hbs group with the class 2. The remaining stem encompasses the bacterial and eukaryotic FHbs and related SDgbs (marked with an aster- isk), including the Cyanidioschyzon and Thalassiosira SDgbs, the separate clusters of plant NsHbs and SHbs (lower right hand side) and all the known metazoan globins, including the vertebrate globins (lower left hand side). Noteworthy is the clustering of bacterial SDgbs with the globin domains of bacterial and eukaryote (fungal, diplomonad and mycetozoan) FHbs, suggestive of past lateral gene transfer events [49]. Likewise, the clustering of the archaeal 2/2 Hbs with the class 1 bacterial 2/2 Hbs, could be indicative of a past lateral gene transfer. Very recently, a $2 / 2 \mathrm{Hb}$ and an $\mathrm{FHb}$ were found in the multicellular red alga Chondrus crispus (X. Bailly et al., unpublished results): these two sequences cluster with the Thalassiosira $2 / 2 \mathrm{Hb}$ and Aquifex SDgb, respectively. An interesting result is the close grouping of Amphitrite ornata dehaloperoxidase [92] with the intracellular hemoglobin of the hydrothermal vent annelid Alvinella pompejana [93], suggesting that the latter may be a dehaloperoxidase also. The Gallus and Xenopus HbX group with the vertebrate Ngbs as found earlier [40]. Of particular interest is the large C. elegans globin family: all except F21A3.6 and ZK637.13, cluster together, and appear to be closest to the vertebrate Ngbs. ZK637.13 groups with globins from other nematode species, F21A3.6 clusters with crustacean (Daphnia and Artemia) and platyhelminth (Paramphistomum and Clonorchis) sequences. It should be noted that the locations of these three globins is dependent on the number of globin sequences used to construct the phylogenetic tree.

We have discussed elsewhere [49] the possible evolutionary scenarios for the emergence of the proposed three lineages of globins in two structural classes: (1) the 3-over-3 SD globins and FHbs, (2) the 3-over-3 GCS/Pgbs, and (3), the 2-over-2 SDgbs. Here, we would like to reiterate our proposal that all metazoan and plant globins originated from a SDgb related to the present day bacterial and algal SDgbs and the N-terminal globin domains of fungal and bacterial FHbs. This proposal is based on two results, one of which, is the clustering of all metazoan and plant sequences with the bacterial and eukaryote FHbs and SDgbs and separate from the branches encompassing $2 / 2$ Hbs and GCSs/Pgbs, in the Bayesian phylogenetic tree obtained earlier [49] and in the one shown in Fig. 5. Another key result, is that bacterial SDgbs and eukaryote FHb globin domains used as queries in iterated psiblast searches, recognize (i.e. have E values substantially lower than threshold) vertebrate globins, particularly Ngbs, and other metazoan globin groups, ahead of the $2 / 2 \mathrm{Hbs}$ and GCSs/Pgbs [49]. Conversely, vertebrate Ngbs as a group, recognize the bacterial SDgbs ahead of other vertebrate globins. Furthermore, the tree shown in Fig. 5 is in very good agreement with recent models of vertebrate globin evolution $[36,62,94]$, wherein duplication of the ancestral globin gene resulted in neuroglobin and cellular globin 


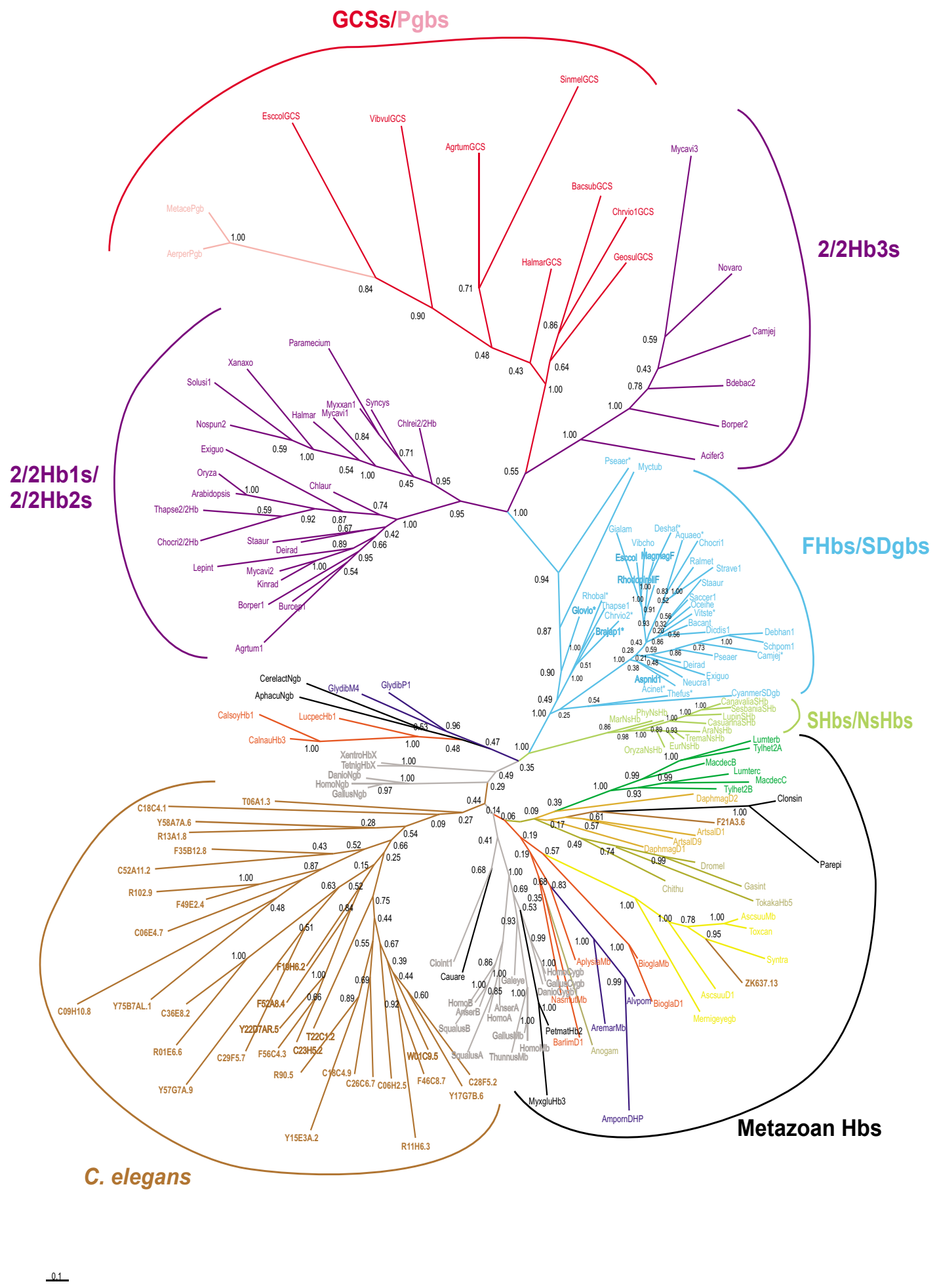

Figure 5

A Bayesian phylogenetic tree based on 175 sequences representing all the known globin families (alignment provided in Supplemental Data Fig. 3). The scale bar represents a distance of 0.1 accepted amino acid mutations per site. The numbers at the nodes represent Bayesian posterior probabillities. 
genes, with subsequent duplication of the latter into cellular and $\mathrm{Hb}$ gene loci, followed by additional duplications of the cellular globin locus into $\mathrm{Mb}$ and Cygb and of the Hb gene into the $\alpha$ - and $\beta$-globin genes.

The first attempt at defining the molecular phylogeny of globins [95] was a tree based on 245 sequences, all from eukaryotes. A subsequent study by Moens et al. [96] based on 700 sequences, including bacterial ones, proposed that all globins «evolved from a family of ancestral, ca. $17 \mathrm{kDa}$ hemeproteins, which displayed the globin fold and functioned as redox proteins». The present survey of extant globins in the three kingdoms of life provides some interesting additional details: we now know that there are three lineages of globins, two with a $3 / 3 \alpha$-helical fold and one with the $2 / 2$ fold, and that only the latter occurs at present in all three kingdoms of life. Furthermore, it appears likely that formation of chimeric proteins containing globin domains occurred, as separate events, prior to the emergence of the three kingdoms of life. There are no obvious explanations for the absence of FHbs in Archaea and of GCSs in eukaryotes. Although it is not possible at present to decide which of the two folds originated from the other, the occurrence of $2 / 2 \mathrm{Hbs}$ in all three kingdoms of life would suggest that it is the ancestral fold. A recent computational study of plant $\mathrm{Hb}$ folding showed that one of the folding modules of rice $3 / 3 \mathrm{NsHb}$ overlaps the $2 / 2$ fold of Mycobacterium tuberculosis $\mathrm{HbO}$ (class 2) suggesting that it is an ancient structural feature of globins [97].

\section{Globin function}

The pesence of multiple globins in all three kingdoms of life raises the question of their function, paticularly among the unicellular organisms. Although a complete discussion is not possible here, some general observations can be made, limited to organisms other than Animalia. The bacterial FHbs appear to have a role primarily in the detoxification of NO, via two NADH dependent activities, an NO dioxygenase activity under aerobic conditions, or an NO reductase activity under anaerobic conditions $[42,43,98-100]$. Furthermore, the recent demonstration that the E. coli FHb binds lipids and is an efficient alkylhydroperoxide reductase, suggests that it may be involved in the repair of lipid membranes damaged by oxidative/nitrosative stress [101-103]. The function(s) of bacterial SDgbs appear to be somewhat similar to the FHbs. Although the function of Vitreoscilla $\mathrm{Hb}$ is to increase the effective intracellular $\mathrm{O}_{2}$ concentration under microaerobic conditions $[42,104]$, that of Campylobacter SDgb was shown recently to function only in NO scavenging and detoxification and not provide resistance against superoxide or peroxides [105]. In eukaryotes, such as yeasts and Dictyostelium, FHbs also provide protection against NO $[43,106,78]$, as well as enhancement of respiration, directly by functioning as an $\mathrm{O}_{2}$ buffer and indirectly, by reducing the NO concentration in the mitochondria which otherwise inhibits respiration [107-110]. In pathogenic microorganisms, $\mathrm{FHb}$ provides protection from human macrophage NO-mediated killing and promotes the virulence of bacteria, e.g. Salmonella [111], and of yeasts, Candida [112] and Cryptococcus neoformans, a worldwide pathogen causing pulmonary infection in animals and humans $[113,114]$. It is interesting to note, as suggested by one of the reviewers, that since most of the Archaea are not pathogenic, they may have dispensed with the FHbs and their protective role in bacteria.

In plants, the SHbs have been shown to be required for establishing a low oxygen concentration for the effective functioning of the bacterial nitrogenase necessary for nitrogen fixation [115]. Although the role of $2 / 2 \mathrm{Hbs}$ in plants is completely unknown, the NsHbs, induced in plant cells upon exposure to low oxygen concentrations, are thought to play a role in a metabolic pathway which also involves nitric oxide and which provides an alternative type of respiration to the mitochondrial electron transport under hypoxic conditions $[116,117]$.

The GCSs represent one of the four known families of heme-based sensors [118], and can be subdivided into two groups, the HemATs and the gene regulators. The former are aerotactic heme sensors, with a C-terminal domain that is related to chemotaxis methyl-accepting proteins. Although Bacillus subtilis HemAT elicits an aerophilic response, that from the archaean Halobacterium salinarum provides an aerophobic response [44,45]. The gene regulators have $\mathrm{C}$-terminal domains, some of which may regulate second messengers and others that have unknown functions $[47,48.59,118]$. Although little is known about the specific function of the Pgbs, they have a Cys at position E19, similar to globins of the annelids living in sulfide-rich environments, including deep sea hydrothermal vents and marine sediments, where this residue has been implicated in sulfide binding $[119,120]$.

Recent studies of Mycobacterium tuberculosis 2/2 Hbs, HbN $(2 / 2 \mathrm{Hb} 1)$ and $\mathrm{HbO}(2 / 2 \mathrm{Hb} 2)$, indicate that the former functions in $\mathrm{NO}$ detoxification, while $\mathrm{HbO}$, which differs substantially from $\mathrm{HbN}$ in structure [121], is expressed in association with cell membranes and significantly enhances respiration, suggesting an interaction with the electron transport chain [122-126]. It remains to be seen whether these findings apply to other bacterial 2/2 Hbs. Although nothing is known about the function of the 2/ $2 \mathrm{Hb} 3 \mathrm{~s}$, it is safe to assume that it must differ from the other two classes, since 32 bacteria have two and Mycobacterium avium ssp. tuberculosis and Methylococcus capsulatus have all three classes of $2 / 2 \mathrm{Hbs}$. 
Finally, it is appropriate to mention here the case of the extracellular $\mathrm{Hb}$ from the nematode Ascaris suum, an octamer of two-domain globin chains, long known for its high oxygen affinity [127], whose function appears to be that of an NO reductase [128], similar to that of fungal and bacterial FHbs. Interestingly FUGUE searches using $\mathrm{FHb}$ and SDgb sequences as queries, invariably include the Ascaris Hb domain 1 structure (1ash) among the highest scoring globin structures. This case provides an additional bit of evidence in support of our proposal that the FHbs and related SDgbs from bacteria, algae and unicellular eukaryotes, including fungi, are part of one of the three globin lineages, and the one from which originated all metazoan globins and all plant SHbs and NsHbs [49].

\section{Conclusion}

The phylogenomic profile derived from our survey of genomes from the three kingdoms of life presented here, delineates the present day limits of the occurrence of the three lineages of globins, and provides a clear view of the work that remains to be done. It appears likely that in contrast to archaea, where $20 \%$ of the known genomes have globins, the majority of bacteria will be shown to have globins. Based on the prevailing opinion that all plants have globins, it is likely that this will also hold true for the unicellular, photosynthesizing eukaryotes. Globin occurrence in other unicellular eukaryotes is likely to be episodic, just as in the case of nonvertebrate metazoans.

Another obvious conclusion is that globins are mostly enzymes and less frequently sensors, and that transport of oxygen is a function that developed relatively recently, accompanying the emergence of multicellular organisms. There are at least two more known instances of evolution from enzyme to transporter. One, is the convergent evolution of indoleamine dioxygenase into a muscle heme protein with Mb-like oxygen binding properties, in gastropod molluscs [129]. Another are hemocyanins, the copper containing respiratory proteins in molluscs and arthropods, which have evolved from phenoloxidases, prior to the divergence of Protostomes and Deuterostomes [130]. The recent finding of hemerythrins, similar to the nonheme iron respiratory protein of Sipunculids, Brachiopods and Priapulids, in the methanotrophic Gammaproteobacterium Methylococcus capsulatus, and in other prokaryotes [131], and also in the hydrothermal vent annelid Riftia pachyptila (X. Bailly et al., unpublished observations), where they may have an enzymatic function, suggests yet another possible instance.

\section{Methods}

Identification of globin sequences

Putative globins and globin domains were identified in the genomes of 49 eukaryotes, 26 archaea and 245 bacteria, listed in Supplementary Data Table 1, using two approaches. In one, we examined the gene assignments based on a library of hidden Markov models [132], listed on the SUPERFAMILY site http://supfam.mrclmb.cam.ac.uk, discarded sequences shorter than 100aa and checked the alignments for the presence of His at Mbfold position F8. In the other, we performed blastp and tblastn (version 9.2.2) searches with pairwise alignment [133], of completed and unfinished genomes in the GenBank, using the NCBI Entrez retrieval system http:// www.ncbi.nlm.nih.gov/BLAST/, including the genomes of the rhodophyte (red alga) Cyanidioschyzon merolae http:// merolae.biol.s.u-tokyo.ac.jp, chlorophyte (green algae) Chlamydomonas reinhardtii http://www.biology.duke.edu/ chlamy/, and the diatoms Phaeodactylum tricornutum http:/ Lavesthagen.szbowler.com and Thalassiosira pseudonana http://genome.jgi-psf.org/thaps1/thaps1.home.html.

Blastp searches use the Expect value (E) to assess the matches between the query sequence and each of the sequences in a database. Thus, $\mathrm{E}=0.1$ signifies that the probability of finding by chance, another match with the query sequence having the same score, is 1 in 10 . We define recognition to be a hit with $\mathrm{E}<0.005$, the default threshold, and with the pairwise alignment fulfilling the following two criteria: proper alignment of the F8 His residues and of helices BC through G. It should be noted that blastp searches often misalign the E helices when the E7 residues are different, e.g. His and Q; however, the rest of the alignment is unaffected.

In cases where the identification of a putative globin was uncertain, searches employing CD-Search v.2.02 [134] http://www.ncbi.nlm.nih.gov, PFAM [135]http:// www.sanger.uc.uk and FUGUE [136] http://wwwcryst.bioc.cam.ac.uk were used to determine whether the borderline sequence should be accepted as a globin.

\section{Alignment of sequences}

The putative globin sequences were aligned manually, using the procedure employed earlier in the alignment of over 700 globins [137], based on the myoglobin fold $[138,139]$, the pattern of predominantly hydrophobic residues at 37 conserved, solvent-inaccessible positions with mean solvent-accessible areas of $<15 \AA^{2}$ [140], including 33 intra-helical residues defining helices A through $\mathrm{H}, \mathrm{A} 8$, A11, A12, A15, B6, B9, B10, B13, B14, C4, E4, E7, E8, E11, E12, E15, E18, E19, F1, F4, G5, G8, G11, G12, G13, G15, G16, H7, H8, H11, H12, H15, and H19, the three interhelical residues at CD1, CD4 and FG4, and the invariant His at F8. Only amino acids which occur at the 33 intrahelical positions in the foregoing alignment were allowed in the alignment of the putative globin sequences. Although earlier alignments by Kapp et al. [137] and by Moens et al. [96] had indicated that there were two invariant residues in globins, $\mathrm{F} 8 \mathrm{His}$ and $\mathrm{CD} 1 \mathrm{Phe}$, the $2 / 2 \mathrm{Hb}$ family can accommodate other hydrophobic residues, 
such as Tyr/Met/Leu/Ile/Val at the CD1 position as well as $\mathrm{Ala} / \mathrm{Ser} / \mathrm{Thr} / \mathrm{Leu}$ at the distal E7 position, in addition to His and Gln [16,20-22]. Hence, in our alignments, we required a His at the proximal $\mathrm{F} 8$ position, a residue at the distal E7 position in the order of preference His $>$ Gln $>$ Leu Thr $>$ Ala Val Ser Tyr, a hydrophobic residue at position $\mathrm{CD} 1$ in the order of preference Phe $>$ Tyr $>$ Leu $>$ Met $>$ Ile $>$ Val. At position C4, usually a Pro, we accepted Ala or Ser or Thr but not a charged residue. At the interhelical position CD4, we sought a hydrophobic residue, when available, and at position FG4 we placed a hydrophobic residue in the order of preference Ile $>$ Leu Val $>$ Met $>$ PhenTyr. Furthermore, we avoided deletions in any of the helical regions and placed no limit on the number of residues within the interhelical regions.

\section{Molecular phylogeny}

Bayesian phylogenetic trees were obtained employing MrBayes Version 3.1.1 [141]; four chains were run simultaneously for 2000000 generations and trees were sampled every 100 generations generating a total of 20000 trees. PAUP version 4.0b10 [142] was used for viewing and editing. The JTT transition matrix [143] was used as the stochastic model of amino acid substitution.

\section{Abbreviations}

Cygb - 3-over-3 cytoglobin; FHb - flavohemoglobin, chimeric proteins ( $400 \mathrm{aa}$ ) comprising a 3-over-3 N-terminal globin and a C-terminal flavin reductase domain; GCS - globin-coupled sensors: chimeric proteins ( 300 to >700aa) comprising a 3-over-3 N-terminal globin domain and a variable $\mathrm{C}$-terminal portion; $\mathrm{Hb}$ - hemoglobin; $\mathrm{SHb}$ - 3-over-3 symbiotic Hbs of legumes and other plants; $\mathrm{Mb}$ - myoglobin; Ngb - 3-over-3 neuroglobin; NsHbs -3over-3 nonsymbiotic plant Hbs; Pgb - protoglobin, single domain 3-over-3 globin related to the N-terminal domain of GCSs; SDgb - 3-over-3 single domain globin ( 140aa) related to the $\mathrm{N}$-terminal of FHbs; $3 / 3 \mathrm{gbs}$ - all globins that have the canonical 3-over-3 $\alpha$-helical fold; $2 / 2 \mathrm{Hbs}-$ "truncated" Hbs that are not necessarily shorter than 140aa, which have the 2-over-2 $\alpha$-helical fold.

\section{Authors' contributions}

SNV identified globin sequences from genomic data and performed the alignments.

DH identified globin sequences and participated in sequence alignment and construction of phylogenetic trees.

$\mathrm{XB}$ identified globin sequences and participated in sequence alignment and construction of phylogenetic trees.
RAP provided systematic input and was involved in the preparation of the MS.

JG participated in the identification of globin sequences.

SD provided systematic input and was involved in the preparation of the MS.

LM provided systematic input and was involved in the preparation of the MS.

JVF provided systematic input and was involved in the preparation of the MS.

\section{Additional material}

\section{Additional File 1}

Table 1. List of genomes from the three kingdoms of life used in the present study. Table 2. Identified and putative globins in archaeal genomes. Table 3. Phylogenomic distribution of identified and putative globins in bacteria. Table 4. Identified and putative globins in eukaryote genomes. Table 5. The putative globin orthologs of Caenorhabditis briggsae and C. elegans Table 6. Identified and putative globins in fungal genomes.

Click here for file

[http://www.biomedcentral.com/content/supplementary/14712148-6-31-S1.doc]

\section{Additional File 2}

Fig. 1. Alignment of selected globin sequences. Fig. 2. Alignment of putative globins from Caenorhabditis briggsae and C. elegans. Fig. 3.

Alignment of 175 representative globin sequences used in the construction of the Bayesian phylogenetic tree shown in Fig. 5.

Click here for file

[http://www.biomedcentral.com/content/supplementary/1471-

2148-6-31-S2.doc]

\section{Acknowledgements}

This work was supported by grants from the Fund for Scientific Research Flanders (G.033I.04), the European Commission (QLG3-CT-2002-0I548) and the Consejo Nacional de Ciencia y Tecnología (project no. 42873-Q), México. SD is a postdoctoral fellow of the Fund for Scientific Research Flanders (FWO).

\section{References}

I. Appleby C: Leghemoglobin and rhizobium respiration. Ann Rev Plant Physiol 1984, 345:443-478.

2. Vinogradov SN, Walz DA, Pohajdak B, Moens L, Kapp O, Suzuki T, Trotman C: Adventitious variability? The amino acid sequences of nonvertebrate globins. Comp Biochem Physiol 1993, B I06: I-26.

3. Weber RE, Vinogradov SN: Nonvertebrate hemoglobins: functions and molecular adaptations. Physiol Rev 2001, 81:569-628.

4. Arredondo-Peter R, Hargrove MS, Moran J, Sarath G, Klucas RV: Plant hemoglobins. Plant Physiol | 998, I | 8: | | 2|- | | 25.

5. Ross E, Lira-Ruan V, Arredondo-Peter R, Klucas R, Sarath G: Recent insights into plant hemoglobins. Rev Plant Biochem Biotechnol 2002, I:173-189.

6. Dordas C, Rivoal J, Hill RD: Plant haemoglobins, nitric oxide and hypoxic stress. Ann Bot (Lond) 2003, 91 :173-178. 
7. Vasudevan S, Armarego W, Shaw D, Lilley P, Dixon N, Poole RK: Isolation and nucleotide sequence of the $\mathrm{hmp}$ gene that encodes a haemoglobin-like protein in Escherichia coli K-I 2. Mol Gen Genet I99I, 226:49-58.

8. Iwaasa $H$, Takagi T, Shikama K: Amino acid sequence of yeast hemoglobin. A twodomain structure. J Mol Biol 1992, 227:948-954.

9. Zhu $\mathrm{H}$, Riggs A: Yeast flavohemoglobin is an ancient protein related to globins and a reductase family. Proc Natl Acad Sci USA 1992, 89:5015-5019.

10. Takagi T: Hemoglobins from single-celled organisms. Curr Opinion Struct Biol 1993, 3:413-418.

II. Potts M, Angeloni S, Ebel R, Bassam D: Myoglobin in a cyanobacterium. Science 1992, 256:1690-1692.

12. Kaneko T, Tabata S: Complete genome structure of the unicellular cyanobacterium Synechocystis sp. PCC6803. Plant Cell Physio 1997, 38: ||7|-1|76.

13. Scott N, Falzone C, Vuletich D, Zhao J, Bryant V, Lecomte JT: Truncated hemoglobin from the cyanobacterium Synechococcus sp. PCC 7002: evidence for hexacoordination and covalent adduct formation in the ferric recombinant protein. Biochemistry 2002, 41:6902-6910.

14. Vandergon T, Riggs C, Gorr T, Colacino J, Riggs A: The mini-hemoglobins in neural and body wall tissue of the nemertean worm Cerebratulus lacteus. J Biol Chem 1998, 273: 16998-I70II.

15. Couture M, Yeh S, Wittenberg BA, Wittenberg JB, Ouellet Y, Rousseau $D$, Guertin $M$ : A cooperative oxygen-binding hemoglobin from Mycobacterium tuberculosis. Proc Natl Acad Sci USA 1999. 96:1223-II228.

16. Wittenberg JB, Bolognesi M, Wittenberg BA, Guertin M: Truncated hemoglobins: a new family of hemoglobins widely distributed in bacteria, unicellular eukaryotes, and plants. J Biol Chem 2002, 277:87।-874.

17. Couture M, Chamberland H, St-Pierre B, Lafontaine J, Guertin M: Nuclear genes encoding chloroplast hemoglobins in the unicellular green alga Chlamydomonas eugametos. Mol Gen Genet 1994, 243:185-197.

18. Couture M, Das T, Lee H, Peisach J, Rousseau D, Wittenberg BA Wittenberg JB, Guertin M: Chlamydomonas chloroplast ferrous hemoglobin. Heme pocket structure and reactions with ligands. J Biol Chem 1999, 274:6898-6910.

19. Watts R, Hunt P, Hvitved A, Hargrove M, Peacock W, Dennis E: A hemoglobin from plants homologous to truncated hemoglobins of microorganisms. Proc Natl Acad Sci USA 200I, 98:10119-101124.

20. Pesce A, Couture M, Dewilde S, Guertin M, Yamauchi K, Ascenzi P, Moens L, Bolognesi M: A novel two-over-two alpha-helical sandwich fold is characteristic of the truncated hemoglobin family. EMBO J 2000, 19:2424-2434.

21. Milani M, Pesce A, Ouellet Y, Ascenzi P, Guertin M, Bolognesi M: Mycobacterium tuberculosi s haemoglobin $\mathbf{N}$ displays a protein tunnel suited for $\mathbf{O}_{2}$ diffusion to the haem. EMBO J 200I, 20:3902-3909.

22. Milani M, Savard P, Oullet H, Ascenzi P, Guertin M, Bolognesi M: A TyrCDI/TrpG8 hydrogen bond network and a TyrBIOTyrCD I covalent link shape the heme distal site of Mycobacterium tuberculosis hemoglobin O. Proc Natl Acad Sci USA 2003, 100:5766-577I.

23. Blaxter ML: Nemoglobins: divergent nematode globins. Parasitology Today 1993, 9:353-360.

24. Kloek A, Sherman D, Goldberg DE: Novel gene structure and evolutionary context of Caenorhabditis elegans globin. Gene |993, | 29:215-22|.

25. Kloek A, McCarter J, Setterquist R, Schedl T, Goldberg DE: Caenorhabditis globin genes: rapid intronic divergence contrasts with conservation of silent exonic sites. J Mol Evol 1996 43: $101-108$.

26. Blaxter ML, Ingram L, Tweedie S: Sequence, expression and evolution of the globins of the parasitic nematode Nippostrongylus brasiliensis. Mol Biochem Parasitol 1994, 68: I-I4.

27. Mansell J, Timms K, Tate W, Moens L, Trotman CN: Expression of a globin gene in Caenorhabditis elegans. Biochem Mol Biol Int 1993, 30:643-647.

28. Vanfleteren JR, Van de Peer Y, Blaxter M, Tweedie S, Trotman C, Lu $L$, Van Hauwaert M, Moens L: Molecular genealogy of some nematode taxa based on cytochrome $c$ and globin amino acid sequences. Mol Phylogenet Evol 1994, 3:92-101.

29. Neuwald A, Liu J, Lipman D, Lawrence C: Extracting protein alignment models from the sequence database. Nucl Acids Re 1997 . 25:1665-1677.

30. Hoogewijs D, Geuens E, Dewilde S, Moens L, Vierstraete A, Vinogradov SN, Vanfleteren JR: Genome-wide analysis of the globin gene family of C. elegans. IUBMB Life 2004, 56:697-702.

3I. Burmester T, Hankeln T: A globin gene of Drosophila melanogaster. Mol Biol Evol 1999, 16:1809-1811.

32. Ebner $B$, Burmester $T$, Hankeln $T$ : Globin genes are present in Ciona intestinalis. Mol Biol Evo 2003, 20:1521-1525.

33. Burmester T, Weich $B$, Reinhardt $\mathrm{S}$, Hankeln $\mathrm{T}$ : A vertebrate globin expressed in the brain. Nature 2000, 407:520-523.

34. Trent J, Watts R, Hargrove M: Human neuroglobin, a hexacoordinate hemoglobin the reversibly binds oxygen. J Biol Chem 200I, 276:30106-30II0.

35. Kawada N, Kristensen D, Asahina K, Nakatani K, Minamiyama Y, Seki $S$, Yoshizato K: Characterization of a stellate cell-activation associated protein (STAP) with peroxidase activity found in rat hepatic stellate cells. J Biol Chem 200I, 276:253 I8-25323.

36. Burmester T, Ebner B, Weich B, Hankeln T: Cytoglobin: a novel globin type ubiquitously expressed in vertebrate tissues. $\mathrm{Mol}$ Biol Evol 2002, 19:416-42I.

37. Trent J, Hargrove MS: A ubiquitously expressed human hexacoordinate hemoglobin. I Biol Chem 2002, 277: 19538-19545.

38. Hankeln T, Ebner B, Fuchs C, Gerlach F, Haberkamp M, Laufs TL, Roesner A, Schmidt M, Weich B, Wystub S, Saaler-Reinhardt S, Reuss S, Bolognesi M, De Sanctis D, Marden MC, Kiger L, Moens L, Dewilde S, Nevo E, Avivi A, Weber RE, Fago A, Burmester T: Neuroglobin and cytoglobin in search of their role in the vertebrate globin family. J Inorg Biochem 2005, 99: I I0-1 I 9.

39. Kugelstadt D, Haberkamp M, Hankeln T, Burmester T: Neuroglobin, cytoglobin, and a novel, eye-specific globin from chicken. Biochem Biophys Res Commun 2004, 325:719-225.

40. Roesner A, Fuchs C, Hankeln T, Burmester T: A globin gene of ancient evolutionary origin in lower vertebrates: evidence for two distinct globin families in animals. Mol Biol Evol 2005, 22: $12-20$.

4I. Poole RK, Hughes MN: New functions for the ancient globin family: bacterial responses to nitric oxide and nitrosative stress. Mol Microbiol 2000, 36:775-783.

42. Frey $A D$, Kallio PT: Bacterial hemoglobins and flavohemoglobins: versatile proteins and their impact on microbiology and biotechnology. FEMS Microbiol Rev 2003, 27:525-545.

43. Wu G, Wainwright L, Poole RK: Microbial globins. Adv Microb Physiol 2003, 47:255-310

44. Hou S, Larsen R, Boudko D, Riley C, Karatan E, Zimmer M, Ordal G, Alam M: Myoglobin-like aerotaxis transducers in Archaea and Bacteria. Nature 2000, 403:540-544.

45. Yu H, Saw J, Hou S, Larsen R, Watts K, Johnson M, Zimmer M, Ordal G, Taylor B, Alam M: Aerotactic responses in bacteria to photoreleased oxygen. FEMS Microbiol Lett 2002, 2 I 7:237-242.

46. Hou S, Freitas T, Larsen R, Piatibratov M, Sivozhelezev V, Yamamoto A, Meleshkevitch E, Zimmer M, Ordal G, Alam M: Globin-coupled sensors: a class of heme-containing sensors in Archaea and Bacteria. Proc Natl Acad Sci USA 200I, 98:9353-9358.

47. Freitas T, Hou S, Alam M: The diversity of globin-coupled sensors. FEBS Lett 2003, 552:99-104.

48. Freitas T, Hou S, Dioum E, Saito J, Newhouse J, Gonzalez G, GillesGonzalez MA, Alam M: Ancestral hemoglobins in Archaea. Proc Natl Acad Sci USA 2004, I 01:6675-6680.

49. Vinogradov SN, Hoogewijs D, Bailly X, Arredondo-Peter R, Guertin M, Gough J, Dewilde S, Moens L, Vanfleteren JR: Three globin lineages belonging to two structural classes in genomes from the three kingdoms of life. Proc Natl Acad SC USA 2005, 102:11385-11389.

50. Baldauf SL, Bjattacharya D, Cockrill J, Hugenholtz D, Pawlowski J, Simpson A: The tree of life. An overview. In Assembling the Tree of Life Edited by: Cracraft J, Donaghue MJ. Oxford University Press, Oxford, UK; 2004:43-75

51. Zhang W, Phillips GN Jr: Structure of the oxygen sensor in Bacillus subtilis. signal transduction of chemotaxis by control of symmetry. Structure 2003, I I:1097-II08.

52. Schleper C, Jurgens G, Jonuscheit M: Genomic studies of uncultivated Archaea. Nature Rev Microbiol 2005, 3:479-488. 
53. Vuletich D, Lecomte JTJ: A phylogenetic and structural analysis of truncated hemoglobins. J Mol Evol 2006, 62:196-210.

54. Lira-Ruan V, Sarath G, Klucas RV, Arredondo-Peter R: In silico analysis of a flavohemoglobin from Sinorhizobium meliloti strain 1021. Microbiol Res 2003, I 58:215-227.

55. Wakabayashi S, Matsubara H, Webster D: Primary sequence of a dimeric bacterial haemoglobin from Vitreoscilla. Nature 322:48I-483.

56. Kim Y, Joachimiak A, Skarina T, Bochkarev A, Savchenko A, Edwards A: Crystal structure of $\mathrm{Pa} 3967$ from Pseudomonas aeruginosa Paol, a hypothetical protein which is highly homologous to human hemoglobin in structure. 2004. unpublished

57. Tarricone C, Galizzi A, Coda A, Ascenzi P, Bolognesi M: Unusual structure of the oxygen-binding site in the dimeric bacterial hemoglobin from Vitreoscilla sp. Structure 1997, 5:497-507.

58. Ilari A, Bonamore A, Farina A, Johnson K, Boffi A: The X-ray structure of ferric Escherichia coli flavohemoglobin reveals an unexpected geometry of the distal heme pocket. J Biol Chem 2002, 277:23725-23732.

59. Ermler U, Siddiqui R, Cramm R, Friedrich B: Crystal structure of the flavohemoglobin from Alcaligenes eutrophus at I.75 A resolution. EMBO J 1995, 14:6067-6077.

60. Vandamme P, Coenye T: Taxonomy of the genus Cupriavidus : a tale of lost and found. Int J Syst Evol Microbiol 2004, 54:2285-2289.

6I. Freitas T, Saito J, Hou S, Alam M: Globin-coupled sensors, protoglobins, and the last universal common ancestor. J Inorg Biochem 2005, 99:23-33.

62. Zhang W, Phillips GN Jr: Structure of the oxygen sensor in Bacillus subtilis. signal transduction of chemotaxis by contro of symmetry. Structure 2003, I I:1097-I I08.

63. Moran NA: Tracing the evolution of gene loss in obligate bacterial symbionts. Curr Opinion Microbiol 2003, 6:5 I 2-5I8.

64. Goh S-H, Lee Y, Bhanu N, Cam M, Desper R, Martin B, Moharram R, Gherman R, Miller JL: A newly discovered human $\alpha$-globin gene. Blood 2005, 106: I 466-1472

65. Brownlie A, Hersey C, Oates A, Paw B, Falick B, Witkowska H, Flint J, Higgs D, Jessen J, Bahary N, Zhu H, Lin S, Zon L: Characterization of embryonic globin genes of the zebrafish. Dev Biol 2003, 255:48-61.

66. Gillemans N, McMorrow T, Tewari R, Wai A, Burgtorf C, Drabek D, Ventress N, Langeveld A, Higgs D, Tan-Un K, Grosveld F, Philipsen S: Functional and comparative analysis of globin loci in pufferfish and humans. Blood 2003, I01:2842-2849.

67. Dehal P, Satou Y, Campbell RK, Chapman J, Degnan B, De Tomaso A Davidson B, Di Gregorio A, Gelpke M, Goodstein DM, Harafuji N, Hastings KE, Ho I, Hotta K, Huang W, Kawashima T, Lemaire P, Martinez D, Meinertzhagen IA, Necula S, Nonaka M, Putnam N, Rash S, Saiga H, Satake M, Terry A, Yamada L, Wang HG, Awazu S, Azumi K Boore J, Branno M, Chin-Bow S, DeSantis R, Doyle S, Francino P, Keys DN, Haga S, Hayashi H, Hino K, Imai KS, Inaba K, Kano S, Kobayashi K, Kobayashi M, Lee BI, Makabe KW, Manohar C, Matassi G, Medina M, Mochizuki Y, Mount S, Morishita T, Miura S, Nakayama A, Nishizaka S, Nomoto H, Ohta F, Oishi K, Rigoutsos I, Sano M, Sasaki A, Sasakura Y, Shoguchi E, Shin-i T, Spagnuolo A, Stainier D, Suzuki MM, Tassy O, Takatori N, Tokuoka M, Yagi K, Yoshizaki F, Wada S, Zhang C, Hyatt PD, Larimer F, Detter C, Doggett N, Glavina T, Hawkins T, Richardson P, Lucas S, Kohara Y, Levine M, Satoh N, Rokhsar DS: The draft genome of Ciona intestinalis: insights into chordate and vertebrate origins. Science 2002, 298:2157-2167.

68. Small D, Moylan T, Vayda M, Sidell BD: The myoglobin gene of the Antarctic icefish, Chaenocephalus aceratus, contains a duplicated TATAAAA sequence that interferes with transcription. J Exp Biol 206: |3।-139.

69. Rubin GM, Yandell MD, Wortman JR, Gabor Miklos GL, Nelson CR, Hariharan IK, Fortini ME, Li PW, Apweiler R, Fleischmann W, Cherry JM, Henikoff S, Skupski MP, Misra S, Ashburner M, Birney E, Bogusk MS, Brody T, Brokstein P, Celniker SE, Chervitz SA, Coates D, Cravchik A, Gabrielian A, Galle RF, Gelbart WM, George RA, Goldstein LS, Gong F, Guan P, Harris NL, Hay BA, Hoskins RA, Li J, Li Z, Hynes RO, Jones SJ, KuehI PM, Lemaitre B, Littleton JT, Morrison DK, Mungall C, O'Farrell PH, Pickeral OK, Shue C, Vosshall LB, Zhang J, Zhao $\mathrm{Q}$, Zheng $\mathrm{XH}$, Lewis $\mathrm{S}$ : Comparative genomics of the eukaryotes. Science 287:2204-22I5.

70. Hankeln T, Jaenicke V, Kiger L, Dewilde S, Ungerechts G, Schmidt M, Urban J, Marden M, Moens L, Burmester T: Characterization of
Drosophila hemoglobin. Evidence for hemoglobin-mediated respiration in insects. J Biol Chem 2002, 277:290I2-290I7.

7I. Richards S, Liu Y, Bettencourt B, Hradecky P, et al.: Comparative genome sequencing of Drosophila pseudoobscura: chromosomal, gene and cis-element evolution. Genome Res 2005, 15:1-18.

72. Trevaskis B, Watts R, Andersson C, Llewellyn D, Hargrove MS, Olson JS, Dennis ES, Peacock WJ: Two hemoglobin genes in Arabidopsis thaliana : the evolutionary origins of leghemoglobins. Proc Natl Acad Sci USA 1997, 94:12230-12234.

73. Arredondo-Peter R, Hargrove M, Sarath G, Moran J, Lohrman J, Olson JS, Klucas RV: Rice haemoglobins. Gene cloning, analysis, and O-binding kinetics of a recombinant protein synthesized in Escherichia coli. Plant Physiol 1997, I I 5:1259-1266.

74. Lira-Ruan V, Ross E, Sarath G, Klucas RV, Arredondo-Peter R: Mapping and analysis of a hemoglobin gene family from Oryza sativa. Plant Physiol Biochem 2002, 40:199-202.

75. Dujon B, Sherman D, Fischer G, Durrens P, Casaregola S, et al. Genome evolution in yeasts. Nature 2004, 430:35-44.

76. Sartori G, Aldegheri L, Mazzotta G, Lanfranchi G, Tournu H, Brown A, Carignani G: Characterization of a new hemoprotein in the yeast Saccharomyces cerevisiae. J Biol Chem 1999, 274:5032-5037.

77. Andersson J, Sjogren A, Davis L, Embley T, Roger RJ: Phylogenetic analyses of diplomonad genes reveal frequent lateral gene transfers affecting eukaryotes. Curr Biol 2003, 31:94-102.

78. lijima M, Shimizu H, Tanaka $Y$, Urushihara $H$ : Identification and characterization of two flavohemoglobin genes in Dictyostelium discoideum. Cell Struct Funct 2000, 25:47-55.

79. Hemmingsen EA: Respiratory and cardiovascular adaptation in hemoglobin-free fish: resolved and unresolved problems. In Biology of Antarctic Fish Edited by: di Prisco G, Maresca B, Tota B. Springer-Verlag, New York; 1991:191-203.

80. Vayda M, Small D, Yuan M, Costello L, Sidell B: Conservation of the myoglobin gene among Antarctic notothenioid fishes. Mol Mar Biol Biotechnol 1997, 6:207-216.

81. diPrisco G, Cocca E, Parker S, Detrich H: Tracking the evolutionary loss of hemoglobin expression by the white-blooded Antarctic icefishes. Gene 2002, 295:|85-19|.

82. Bargelloni L, Lecointre G: Four years of notothenioid systematics: a molecular perspective. In Fishes of Antarctica Edited by: di Prisco G, Pisano E, Clarke A. Springer-Verlag Italia, Milan, Italy; 1998:259-273.

83. Bishop J, Vandergon T, Green D, Doeller J, Kraus D: A high-affinity hemoglobin is expressed in the notochord of amphioxus, Branchiostoma californiense. Biol Bull 1998, 195:255-259.

84. Baker S, Terwilliger NB: Hemoglobin structure and function in the rat-tailed sea cucumber Paracaudina chilensis. Biol Bull 1993, 185: I15-122

85. Christensen A, Colacino J, Bonaventura C: Functional and biochemical properties of the hemoglobins of the burrowing brittle star Hemipholis elongata Say (Echinodermata, Ophiuroidea). Biol Bull 2003, 205:54-65.

86. Nielsen E, Mound L: Global diversity of insects: the problem of estimating numbers. In Nature and Human Society: The Quest for a Sustainable World Edited by: Raven PH. National Academy Press, Washington, DC; 1997:213-222.

87. Moreira D, Lopez-Garcia P: The molecular ecology of microbial eukaryotes unveils a hidden world. Trends Microbiol 2002, 10:31-38.

88. Falkowski P, Katz M, Knoll A, Quigg A, Raven J, Schofield O, Taylor F: The evolution of modern eukaryotic phytoplankton. Science 2004, 305:354-360.

89. Uma S, Matts R, Guo Y, White S, Chen Jl: The N-terminal region of the heme-regulated elF2alpha kinase is an autonomous heme binding domain. Eur J Biochem 2000, 267:498-506.

90. Rafie-Kolpin M, Chefalo P, Hussain Z, Hahn J, Uma S, Matts R, Chen Jj: Two heme-binding domains of heme-regulated eukaryotic initiation factor-2alpha kinase. $\mathbf{N}$ terminus and kinase insertion. I Biol Chem 2000, 275:5I7I-5I78.

9I. Inuzuka T, Yun B, Ishikawa H, Takahashi S, Hori H, Matts R, Ishimori $\mathrm{K}$. Morishima I: Identification of crucial histidines for heme binding in the $\mathrm{N}$-terminal domain of the heme-regulated elF2alpha kinase. J Biol Chem 2004, 279:6778-6782.

92. LaCount M, Zhang E, Chen Y, Han K, Whitton M, Lincoln D, Woodin $S$, Lebioda $L$ : The crystal structure and amino acid sequence of 
dehaloperoxidase from Amphitrite ornat $a$ indicate common ancestry with globins. J Biol Chem 2000, 27:187/2-187/6.

93. Hourdez S, Lallier F, De Cian M, Green B, Weber R, Toulmond A: Gas transfer system in Alvinella pompejana: functional properties of intracellular and extracellular hemoglobins. Physiol Biochem Zool 2000, 73:365-373.

94. Hardison RC: Organization, evolution and regulation of the globin genes. In Disorders of Hemoglobin Edited by: Steinberg $\mathrm{MH}$ Forget BG, Higgs DR, Nagel RL. Cambridge University Press, Cambridgge, UK; 200I:95-I I6.

95. Goodman M, Pedwaydon J, Czelusniak J, Suzuki T, Gotoh T, Moens L, Shishikura F, Walz DA, Vinogradov SN: An evolutionary tree for invertebrate globin sequences. J Mol Evol 1988, 27:236-249.

96. Moens L, Vanfleteren J, Van de Peer Y, Peeters K, Kapp O, Czeluzniak J, Goodman M, Blaxter M, Vinogradov SN: Globins in nonvertebrate species: dispersal by horizontal gene transfer and evolution of the structure-function relationships. Mol Biol Evol 1996, I 3:324-333.

97. Nakajima S, Álvarez-Salgado E, Kikuchi T, Arredondo-Peter R: Prediction of folding pathway and kinetics among plant hemoglobins using an average distance map method. Proteins Struct Funct Bioinfor 2005, 61:500-506.

98. Farres J, Rechsteiner M, Herold S, Frey AD, Kallio PT: Ligand binding properties of bacterial hemoglobins and flavohemoglobins. Biochemistry 2005, 44:4I 25-4I34.

99. Gardner PM: Nitric oxide dioxygenase function and mechanism of flavohemoglobins, hemoglobins, myoglobins and their associated reductases. J Inorg Biochem 2005, 99:247-266.

100. Poole RK: Nitric oxide and nitrosative stress tolerance in bacteria. Biochem Soc Trans 2005, 33:176-180.

101. Bonamore A, Gentili P, Ilari A, Schinina M, Boffi A: Escherichia coli flavohemoglobin is an efficient alkylhydroperoxide reductase. J BiolChem 2003, 278:22272-22277.

102. Bonamore A, Farina A, Gattoni M, Schinina M, Bellelli A, Boffi A Interaction with membrane lipids and heme ligand binding properties of Escherichia coli flavohemoglobin. Biochemistry 2003, 42:5792-580I.

103. D'Angelo P, Lucarelli D, della Longa $S$, Benfatto $M$, Hazemann J, Feis A, Smulevich G, llari A, Bonamore A, Boffi A: Unusual heme ironlipid acyl chain coordination in Escherichia coli flavohemoglobin. Biophys J 2004, 86:3882-3892.

104. Frey AD, Kallio PT: Nitric oxide detoxification - a new era for bacterial globins in biotechnology? Trends Biotechnol 2005, 23:69-73.

105. Elvers K, Wu G, Gilberthorpe N, Poole RK, Park SF: Role of an inducible single-domain hemoglobin in mediating resistance to nitric oxide and nitrosative stress in Campylobacter jejuni and Campylobacter coli. J Bacteriol 2004, 186:5332-534I.

106. Wu G, Wainwright L, Membrillo-Hernández J, Poole RK: Bacterial hemoglobins: old proteins with "new" functions? Roles of respiratory and nitric oxide metabolism. In Respiration in Archea and Bacteria, Diversity of Prokaryotic Electron Transport Carriers Volume I. Edited by: Zanoni D. Academic Press, London, UK; 2004:255-3I0.

107. Buisson N, Labbe-Bois R: Flavohemoglobin expression and function in Saccharomyces cerevisia e. No relationship with respiration and complex response to oxidative stress. J Biol Chem 1998, 273:9527-9533.

108. Elvers K, Turner S, Wainwright L, Marsden G, Hinds J, Cole J, Poole RK, Penn C, Park SF: NssR, a member of the Crp-Fnr superfamily from Campylobacter jejuni, regulates a nitrosative stress-responsive regulon that includes both a single-domain and a truncated haemoglobin. Mol Microbiol 2005, 57:735-750.

109. Liu L, Zeng M, Hausladen A, Heitman J, Stamler J: Protection from nitrosative stress by yeast flavohemoglobin. Proc Natl Acad Sci USA 2000, 97:4672-4676.

110. Shikama K, Matsuoka A: Structure-function relationships in unusual nonvertebrate globins. Crit Rev Biochem Mol Biol 2004, 39:217-259.

III. Stevanin T, Poole RK, Demoncheaux E, Read R: Flavohemoglobin Hmp protects Salmonella enterica serovar typhimurium from nitric oxide-related killing by human macrophages. Infect Immun 2000, 70:4399-4405.

I 12. Ullmann B, Myers H, Chiranand W, Lazzell A, Zhao Q, Vega L, LopezRibot J, Gardner PR, Gustin M: Inducible defense mechanism against nitric oxide in Candida albicans. Eukaryote Cell 2004 3:7I5-723.
113. de Jesus-Berrios M, Liu L, Nussbaum J, Cox G, Stamler J, Heitman J: Enzymes that counteract nitrosative stress promote fungal virulence. Curr Biol 2003, 13:1963-1968.

I I4. Idnurm A, Reedy J, Nussbaum J, Heitman J: Cryptococcus neoformans virulence gene discovery through insertional mutagenesis. Eukaryote Cell 2004, 3:420-429.

II5. Ott T, van Dongen J, Gunther C, Krusell L, Desbrosses G, Vigeolas H, Bock V, Czechowski T, Geigenberger P, Udvardi MK: Symbiotic leghemoglobins are crucial for nitrogen fixation in legume root nodules but not for general plant growth and development. Curr Biol 2005, 15:531-5.

1 16. Kundu S, Trent J, Hargrove M: Plants, humans and hemoglobins. Trends Plant Sci 2003, 8:387-393.

117. Igamberdiev A, Baron K, Manac'h-Little N, Stoimenova M, Hill RD: The haemoglobin/nitric oxide cycle: involvement in floooding stress and effects of hormone signaling. Ann Bot 2005, 96:557-564.

I I8. Gilles-Gonzalez MA, Gonzalez G: Heme-based sensors: defining characteristics, recent developments, and regulatory hypotheses. J Inorg Biochem 2005, 99: I-22.

119. Bailly X, Jollivet D, Vanin S, Deutsch J, Zal F, Lallier F, Toulmond A: Evolution of the sulfide-binding function within the globin multigenic family of the deep-sea hydrothermal vent tubeworm Riftia pachyptila. Mol Biol Evol 2002, 19:142I-I433.

120. Bailly X, Leroy R, Carney S, Collin O, Zal F, Toulmond A, Jollivet D: The loss of the hemoglobin $\mathrm{H}_{2}$ S-binding function in annelids from sulfide-free habitats reveals molecular adaptation driven by Darwinian positive selection. Proc Natl Acad Sci USA 2003, 100:5885-5890.

121. Lecomte JTL, Vuletich D, Lesk AM: Structural divergence and distant relationships in proteins: evolution of the globins. Curr Opinion Struct Biol 2005, I 5:290-30I.

122. Ouellet $H$, Ouellet $Y$, Richard C, Labarre M, Wittenberg BA, Wittenberg JB, Guertin M: Truncated hemoglobin $\mathrm{HbN}$ protects Mycobacterium bovis from nitric oxide. Proc Natl Acad Sci USA 2002, 99:5902-5907.

123. Pathania R, Navani N, Rajamohan G, Dikshit KL: Mycobacterium tuberculosis hemoglobin $\mathrm{HbO}$ associates with membranes and stimulates cellular respiration of recombinant Escherichia coli. J Biol Chem 2002, 277:I5293-15302.

124. Pathania R, Navani N, Gardner AM, Gardner PR, Dikshit KL: Nitric oxide scavenging and detoxification by the Mycobacterium tuberculosis haemoglobin. Mol Microbiol 2002, 45: |303-13|4.

125. Milani M, Pesce A, Ouellet H, Guertin M, Bolognesi M: Truncated hemoglobins and nitric oxide action. IUBMB Life 2003, 55:623-627.

126. Mukai M, Savard P, Ouellet H, Guertin M, Yeh S: Unique ligandprotein interactions in a new truncated hemoglobin from Mycobacterium tuberculosis. Biochemistry 2002, $41: 3897-3905$.

127. Goldberg DE: Oxygen-avid hemoglobin of Ascaris. Chem Rev 1999, 99:337I-3378.

128. Minning D, Gow A, Bonaventura J, Braun R, Dewhirst M, Goldberg D, Stamler J: Ascaris haemoglobin is a nitric oxide-activated 'deoxygenase'. Nature 1999, 40 I:497-502.

129. Suzuki T, Imai K: Evolution of myoglobin. Cell Mol Life Sci 1998, 54:979-1004

130. Immesberger A, Burmester T: Putative phenoloxidases in the tunicate Ciona intestinali $s$ and the origin of the arthropod hemocyanin superfamily. J Comp Physiol 2004, B I 74: I69-I80.

I3I. Karlsen O, Ramsevik L, Bruseth L, Larsen $\varnothing$, Brenner A, Berven F, Jensen $\mathrm{H}$, Lillhaug J: Characterization of a prokaryotic haemerythrin from the methanotrophic bacterium Methylococcus capsulatu s (Bath). FEBS J 2005, 272:2428-2440.

132. Gough J, Karplus K, Hughey R, Chothia C: Assignment of homology to genome sequences using a library of hidden Markov models that represent all proteins of known structure. J Mol Biol 2001, 313:903-919.

133. Altschul SF, Madden TL, Schäffer AA, Zhang J, Zhang Z, Miller W, Lipman DJ: Gapped BLAST and PSI-BLAST: a new generation of protein database search programs. Nucleic Acids Res 1997, 25:3389-3402.

134. Marchler-Bauer A, Bryant S: CD-Search: protein domain annotations on the fly. Nucleic Acids Res 2004, 32:W327-33I.

135. Bateman A, Birney E, Cerruti L, Durbin R, Etwiller L, Eddy S, GriffithsJones S, Howe K, Marshall M, Sonnhammer E: The Pfam protein families database. Nucleic Acids Res 2002, 30:276-280. 
136. Shi J, Blundell T, Mizuguchi K: FUGUE: sequence-structure homology recognition using environment-specific substitution tables and structure-dependent gap penalties. J Mol Biol 200I, 3 I 0:243-257.

137. Kapp O, Moens L, Vanfleteren J, Trotman C, Suzuki T, Vinogradov $\mathrm{SN}$ : Alignment of $\mathbf{7 0 0}$ globin sequences: extent of amino acid substitution and its correlation in volume. Protein Sci 1995, 4:2179-2190.

138. Lesk AM, Chothia C: How different amino acid sequences determine similar protein structures. The structure and evolutionary dynamics of the globins. J Mol Biol 1980, 136:225-270.

139. Bashford D, Chothia C, Lesk AM: Determinants of a protein fold. Unique features of the globin amino acid sequences. J Mol Biol 1987, 196:199-216.

140. Gerstein M, Sonnhammer ELL, Chothia C: Volume changes in protein evolution. J Mol Biol 1994, 236: 1067-1078.

14I. Huelsenbeck JP, Ronquist F: MRBAYES: Bayesian inference of phylogenetic trees. Bioinformatics 2001, 17:754-755.

142. Swofford D: Phylogenetic Analysis Using Parsimony. In Ver.4.0b 10 Sinauer Associates; 200I.

143. Jones DT, Taylor WR, Thornton JM: The rapid generation of mutation data matrices from protein sequences. Cabios 1992, 8:275-282.

144. Singleton P, Sainsbury D: Dictionary of Microbiology and Molecular Biology. 3rd edition. J. Wiley \& Sons, Chichester, UK; $200 \mathrm{I}$.

145. Singleton P: Bacteria in Biology, Biotechnology and Medicine. 6th edition. J. Wiley \& Sons, Chichester, UK; 2004.

146. Jaillon O, Aury J-M, Brune F, et al.: Genome duplication in the teleost fish Tetraodon nigroviridis reveal the early veertebrate proto-karyotype. Nature 2004, 43 I:946-975.

147. Kellis M, Patterson N, Endrizzi M, Birren B, Landers ES: Sequencing and comparison of yeast species to identify genes and regulatory element. Nature 2003, 423:24I-254.

Publish with Bio Med Central and every scientist can read your work free of charge

"BioMed Central will be the most significant development for disseminating the results of biomedical research in our lifetime. "

Sir Paul Nurse, Cancer Research UK

Your research papers will be:

- available free of charge to the entire biomedical community

- peer reviewed and published immediately upon acceptance

- cited in PubMed and archived on PubMed Central

- yours - you keep the copyright

Submit your manuscript here:

http://www.biomedcentral.com/info/publishing_adv.asp
BiolMedcentral 